\title{
Influence of Shape, Color, Size and Relative Position of Elements on Their Counting by an Ant
}

\author{
Marie-Claire Cammaerts ${ }^{1} \&$ Roger Cammaerts ${ }^{2}$ \\ ${ }^{1}$ Independent researcher, retired from the Biology of Organisms Department, University of Brussels, Belgium \\ ${ }^{2}$ Independent researcher, retired from the Natural and Agricultural Environmental Studies Department (DEMNA) \\ of the Walloon Region, Belgium \\ Correspondence: Marie-Claire Cammaerts, independent researcher, 27, Square du Castel Fleuri, 1170 Bruxelles, \\ Belgium. Tel: 32-2-673-4969. E-mail: mccammaerts@gmail.com
}

Received: February 15, $2020 \quad$ Accepted: February 29, $2020 \quad$ Online Published: March 17, 2020

doi:10.5539/ijb.v12n2p26 URL: https://doi.org/10.5539/ijb.v12n2p26

\begin{abstract}
It was previously shown that workers of the ant Myrmica sabuleti can discriminate small numbers of elements during testing when these elements were identical to those learned during training. Here we examine if this numerosity ability still subsists if the shape, color, size or location of the elements (dots) to count are modified between training and testing. We found that the ants' counting ability was not significantly affected by changing one of these features although a somewhat lesser ability was observed. Among the changes, it was that of the relative position of the elements which disrupted the most the ants' counting ability, followed by a change of their size. A change in the color or the shape affected the least the ants' counting. These impacts of feature changes in the learned cues on the ants' counting can be explained by characteristics of the visual perception of the species as well as by its behavioral ecology.
\end{abstract}

Keywords: Extraneous Variables, Myrmica sabuleti, Numerosity, Operant Conditioning, Visual Perception

\section{Introduction}

Workers of the ant Myrmica sabuleti Meinert 1861 can distinguish different numbers and shapes of elements (Cammaerts, 2008). They can also add and subtract visual elements when having clearly sighted the result of the operation during training (Cammaerts \& Cammaerts, 2019b, c, e). These findings were obtained using cues of identical shape, color, size and location during training and testing. However, the ants may have memorized a displayed image without having sensu stricto counted the presented elements.

It was thus imperative to examine if these ants could also discriminate numbers of elements when those presented during testing differ from those used for training by their shape, size, color or relative position. Such kind of control for extraneous variables co-varying with counting has already been done in studies on numerosity perception involving some invertebrates, vertebrates and humans. Some species tested for their numerosity abilities could be controlled for co-variates by the introduction of simple changes in the presented cues, such as varying their size (in a spider: Rodríguez, Briceño, Briceño-Aguilar, \& Höbel, 2015; in chimpanzees: Tomonaga, 2008), as well as their pattern (in pigeons: Emmerton \& Renner, 2006; in gorillas and orangutans: Gazes, Diamond, Hope, Caillaud, Stoinski, \& Hampton, 2017), or for food items, by changing their nature (in a grey parrot: Pepperberg, 2012) or pictures representing them (in an elephant: Irie, Hiraiwa-Hasegawa, \& Kutsukake, 2019). Numerosity in other species was controlled for shape, size, brightness and location of presented cues (in a mosquito fish: Agrillo, Dadda, Serena, \& Bisazza, 2009) or needed to be controlled with the help of time interval and dummies (in dogs and wolves: Range, Jenikejew, Schröder, \& Virányi, 2014). When testing rhesus and snow monkeys, more elaborated changes including shape, size, cumulative surface (area), color and pattern of displayed cues were used (Brannon \& Terrace, 1998, 2000), as well as density (Cantlon \& Brannon, 2006; Jordan \& Brannon, 2006), linearity of pattern (Nieder, Freedman, \& Miller, 2002) and cumulative perimeter (Okuyama, Kuki, \& Mushiake, 2015). Volume of food items was also taken into account (Flombaum, Junge, \& Hauser, 2005). Crows were also tested with variable size, area, density and linearity of dot displays (Ditz \& Nieder, 2015). Honeybees were tested using different shape, size, color, pattern surface and display of cues (Howard, Avarguès-Weber, Garcia, Greentree, \& Dyer, 2019). As for numerosity in humans, control for extraneous variables took account on the individuals' age. No control could be used for neonates (0 to 3-days old). For 6 - 8-months infants, size and 
pattern displayed (Xu \& Spelke, 2000) including spacing of displayed dots (Rugani \& de Hevia, 2017) were used. Preschool children were tested using variable size, color and displayed pattern (Merritt \& Brannon, 2013) and adults could be tested using different size, cumulative surface and perimeter, density, and displayed pattern (Cantlon \& Brannon, 2006; Merten \& Nieder, 2008).

In the case of the ant Myrmica sabuleti, numerosity abilites (same references as above) were shown without changing between training and testing the features of the elements to count. In the present work on recognition ability between 1 to 4 elements, we changed the shape, color, size and position of cues between training and testing, however only one of these changes being made at a time, in order to assess the effect of each of these changes on the ants' discrimination between numbers.

\section{Material and Methods}

\subsection{Collection and Maintenance of Ants}

The experiments were performed on colonies collected in September 2019 in abandoned quarries at Marchin (Condroz, Belgium) and at Olloy/Viroin (Ardenne, Belgium). Six of the collected colonies contained $200-500$ workers, a queen and brood. Another colony contained more than 2,000 workers, brood and several queens, and was divided in six smaller colonies. Twelve experimental colonies were thus maintained in the laboratory, each in two to three glass tubes half filled with water, a cotton plug separating the ants from the water. The nest tubes of each colony were set in a tray $(34 \mathrm{~cm} \times 23 \mathrm{~cm} \times 4 \mathrm{~cm}$ or $30 \mathrm{~cm} \times 15 \mathrm{~cm} \times 5 \mathrm{~cm})$ which served as foraging area, food being available on it as pieces of Tenebrio molitor larvae (Linnaeus, 1758) deposited three times per week and as, permanently set, a cotton plugged tube filled with sugar water. The ambient temperature was $c a 20^{\circ} \mathrm{C}$, the humidity $80 \%$, the lighting 330 lux while working on ants, and the electromagnetism $2 \mu \mathrm{Wm}^{2}$. These environmental conditions were optimum for the species.

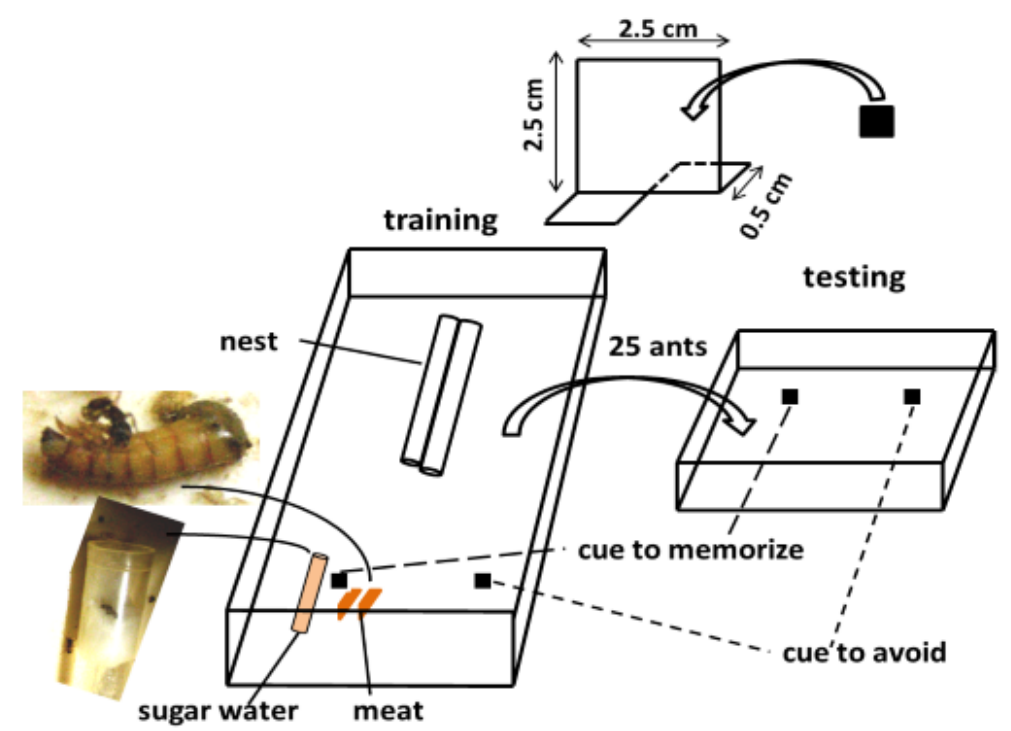

Figure 1. Experimental design used for examining if ants distinguish different numbers of elements whatever their shape, color, size or location

The ants were trained on their foraging area to a number of elements set near the food $v s$ another number set far from food. They were tested in a separate tray faced with two cues having the same number of elements, but these elements differed by their shape, color, size, or relative position from those used for training (one difference being used at a time). The elements presented to the ants were each time tied to a stand (upper part of the schema) maintained vertically thanks to a duly horizontally folded base. Details are given in the text, cues are schematized in Figure 2, and photos of the experiments are shown in Figure 3.

\subsection{Training and Testing}

The ants were continuously trained on their foraging area (operant conditioning) during two days: a stand bearing the cue (see below) they are expected to memorize (i.e. the 'correct' cue) was set near the food and another stand bearing the cue they should not memorize (i.e. the 'wrong' cue) was set far from the food (Figure 1, lower left part; Figure 3, the upper photo for each colony). Each training day, the ants present in the vicinity of the two presented 
cues were counted several times per day, and the mean of these counts was established. These means are given in the text only and did not require statistical analysis.

After 7, 24, 31, and 48 training hours, the ants were tested in a separated tray $(21 \mathrm{~cm} \mathrm{x} 15 \mathrm{~cm} \mathrm{x} 7 \mathrm{~cm})$. the borders of which having been slightly covered with talc to prevent escaping. Each tray contained two stands bearing cues differing by one characteristic from those presented during training (see below) and set at about seven centimeters from one another (Figure 1, lower right part; Figure 3, the lower photo for each colony). To make a test, 25 ants of the experimented colony were transported into the tray devoted to testing and the ants approaching each of the two stands at a distance of at most $2 \mathrm{~cm}$ were counted twenty times over ten minutes (Table 1). The twenty counts relative to the two cues allowed establishing the ants' proportion of correct responses (i.e. the ants' responses to the number of elements identical to that set near the food during training), a proportion given only in the text. The numbers of elements corresponding to those presented during training were randomly located on the left or on the right in the tray devoted to testing. After each test, the ants were immediately returned into their foraging area, very near their nest entrance. After having made the four tests (i.e. after 7, 24, 31, and 48 training hours) on a colony, the average of the ants' conditioning scores ( $\%$ of correct responses) was calculated (Table 1 , last column).

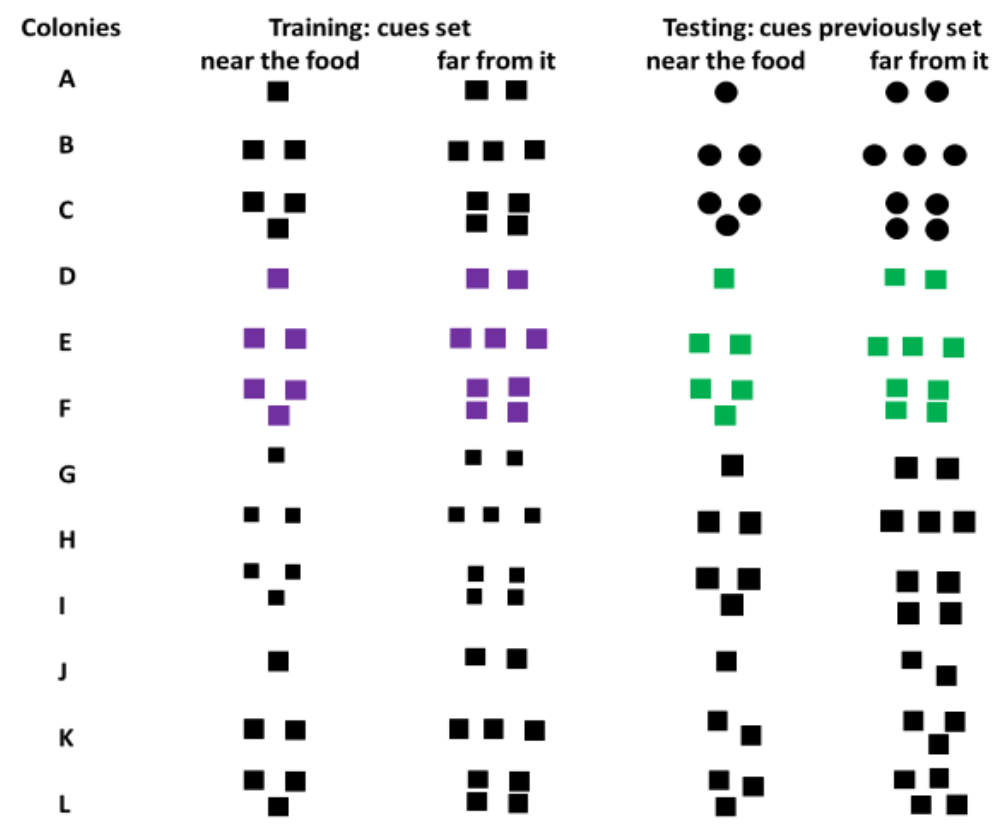

Figure 2. Cues (numbers of elements) presented to the ants, during training and testing

These experiments were made to examine if the ants' discrimination between two numbers of elements was not impacted by extraneous characteristics (shape, color, size, location) of these elements. The elements set near the food during training were the 'correct' cues; those set far from food were the 'wrong' cues. During each test, the presented elements differed by one characteristic. Details (methods, results, statistics, and explanations) are given in the text and the Appendix; photos of the experiments are shown in Figure 3.

\subsection{Cues Presented to the Ants}

Each cue presented to the ants was drawn in a paper square $(2.5 \mathrm{~cm} \times 2.5 \mathrm{~cm})$ using Word $®$ software. They were then printed, cut, and tied on the front face of a stand (Figure 1, upper part; Figure 3). Each stand was made of strong white paper $($ Steinbach $囚)$, had a vertical $(2.5 \mathrm{~cm} \times 2.5 \mathrm{~cm})$ part, and kept its verticality thanks to a duly folded horizontal part $[2 \times(1.25 \mathrm{~cm} \times 0.5 \mathrm{~cm})]$ (same Figures). The cues presented to the different colonies are schematized in Figure 2; these presentations and their aim were as follows.

For examining the influence of the shape of elements on the ants' counting ability, respectively 1,2, and 3 black squares $(0.5 \mathrm{~cm} \times 0.5 \mathrm{~cm})$ were presented during training to colonies $\mathrm{A}, \mathrm{B}$, and $\mathrm{C}$ near their food (= the numbers of elements to memorize, i.e. the 'correct number') and 2, 3, and 4 of such squares far from the food. During testing, the ants of colonies A, B, C were confronted to respectively 1,2 and 3 black circles ( $66 \mathrm{~mm}$ ) (the 'correct cue') versus 2,3 and 4 of such circles. 
To study the influence of the color of elements on the ants' counting ability, respectively 1,2 , and 3 violet squares $(0.5 \mathrm{~cm} \times 0.5 \mathrm{~cm})$ were presented during training to colonies D, E, and F near their food (= the numbers of elements to memorize, i.e. the 'correct number') and 2, 3, and 4 such squares far from the food. During testing, the ants of colonies D, E, F were confronted to respectively 1,2 and 3 green squares $(0.5 \mathrm{~cm} \times 0.5 \mathrm{~cm})$ (the 'correct cue') versus 2, 3 and 4 such squares. Myrmica sabuleti workers have been shown to discriminate colors, even under low light intensity (Cammaerts, 2007; M.-C. Cammaerts \& D. Cammaerts, 2009).

For examining the influence of the size of elements on the ants' counting ability, colonies G, H, I received during training respectively 1,2 and 3 black squares $(0.3 \mathrm{~cm} \times 0.3 \mathrm{~cm})$ near their food (the numbers of elements to count and memorize) and 2, 3 and 4 of such squares far from the food, and during testing, the ants of these colonies $\mathrm{G}, \mathrm{H}$, I were confronted to respectively 1,2 and 3 larger black squares $(0.5 \mathrm{~cm} \times 0.5 \mathrm{~cm})$ ( the 'correct cue') versus 2,3 and 4 of such larger black squares.

In order to assess on the ants' counting ability the effect of a change in the relative position of elements displayed on a stand, the colonies $\mathrm{J}, \mathrm{K}, \mathrm{L}$ were provided during training with respectively 1,2 and 3 black squares $(0.5 \mathrm{~cm} \times$ $0.5 \mathrm{~cm}$ ) set near the food (the number to memorize) and with 2, 3 and 4 such squares set far from the food. The ants of these colonies J, K, L were tested in front of respectively 1,2 and 3 black squares $(0.5 \mathrm{~cm} \times 0.5 \mathrm{~cm})$ (the 'correct cue') which relative position on the stand differed from that during training versus 2,3 and 4 of such squares differently positioned.

\subsection{Statistical Analysis}

The effect of changes in shape, color, size or relative position of the elements on the ants' counting ability (i.e. on their choice of the correct versus the wrong numbers of elements) was separately analyzed for 1 vs 2, 2 vs 3 and 3 vs 4 elements and for 7, 24, 31 or 48 training hours. The twenty numbers chronologically obtained for each kind of stand were summed by four, and the five values obtained for a stand were compared to those obtained for the other stand using the non-parametric test of Wilcoxon (Siegel \& Castellan, 1989). The results of these tests are given in the Appendix.

We also compared to one another the impact of the four kinds of changes made to the elements. As the counting of the tested ants present at close proximity of the stands bearing the correct and the wrong number of elements corresponded to the sum of the number of workers sighted in the course of $10 \mathrm{~min}$, such a counting inflated the number of ants present at a given time near each stand, although providing a more comfortable computation size when using statistical tests. However, all the protocols and counting were identical, what allowed comparison. Moreover, the workers counted during 10 minutes were not necessarily those staying close to each of the two stands, as they could walk from one stand to the other. Thus, the numbers of ants counted near the correct and the wrong numbers of elements were not entirely independent. Nevertheless, as all the other variables were independent from each other, the non-parametric Chi-square test for independent samples appeared to be a practical choice. This test was thus used to compare the ants' correct and incorrect choices in relation with the four changes. Moreover, the Chi-square test for 2 x 2 contingency tables (Siegel \& Castellan, 1989) was used to compare only the changes which leaded to the highest difference in the ants' average $\%$ of correct responses, i.e. the changes in shape and in relative position. Furthermore, for reducing as much as possible the non-independent character of the number of ants observed near each stand, we used the exact probability Fisher test (same reference as above) for a comparison between every two kinds of change, by taking into account the number of ants sighted during only the first two minutes of their counting, thus at a time when their walking to another stand was the most limited. These small numbers of ants corresponded to the first number of each five counts related in the Appendix.

\section{Results}

Numerical results are given in Table 1, photos of the experiments are shown in Figure 3, numerical and statistical details are related in the Appendix located at the end of the present paper.

\subsection{Discrimination of Numbers of Elements Whatever Their Shape}

During their training to $1 v s$ black squares, the ants of colony A were sufficiently numerous at any time around the two presented cues for seeing and memorizing them. Tested after 7, 24, 31, and 48 training hours in front of 1 and 2 black circles, these ants went essentially to the 1 black circle (Table 1, line 1), and presented a conditioning score of $67.8 \%, 78.7 \%, 74.0 \%$ and $81.8 \%$ respectively. Each time, the counts corresponding to these scores were statistically significant $(\mathrm{P}=0.031)$. The average ants' conditioning score over their entire training equaled $77.3 \%$. During their training to 2 vs 3 black squares, the ants of colony B were numerous enough all around these two cues to see and memorize them. Tested after 7, 24, 31, and 48 training hours in front of 2 and 3 black circles, these ants reacted essentially to the 2 circles (Table 1 , line 2). They presented a conditioning score of $70 \%, 80.3 \%, 68.9 \%$ and 
$79.3 \%$ respectively, the counts corresponding to these scores being each time statistically significant $(\mathrm{P}=0.031)$. Over their 48 training hours, the ants presented an average conditioning score of $73.8 \%$. While being trained to $3 v s$ 4 black squares, the ants of colony $\mathrm{C}$ were numerous enough in the vicinity of these two cues for seeing and memorizing them. Tested after 7, 24, 31 and 48 training hours faced with 3 and 4 black circles, these ants went mostly to the 3 circles (Table 1, line 3), and presented a conditioning score of $68.1 \%, 71.6 \%, 69.4$ and $73.8 \%$ respectively, the counts corresponding to these scores being statistically significant $(\mathrm{P}=0.031)$. The ants' average conditioning score for their entire training time equaled $70.9 \%$. We can thus conclude that the ants of colonies A, B, and $C$ distinguished respectively 1, 2 and 3 elements from 2, 3 and 4 elements, and thus correctly counted them, i.e. independently of their shape (squares or circles).

\subsection{Discrimination of Numbers of Elements Whatever Their Color}

While being trained to 1 vs 2 violet squares, the ants of colony D were sufficiently numerous all around these two cues for seeing and memorize them. Tested faced with 1 and 2 green squares after successively 7, 24, 31, and 48 training hours, these ants went mostly to the 1 green square (Table 1, line 4), presenting a conditioning score of $70.8 \%, 75.4 \%, 85.1 \%$, and $77.2 \%$ respectively. The counts corresponding to these scores were statistically significant $(\mathrm{P}=0.031)$. The ants' average conditioning score assessed over the entire training time equaled $77.2 \%$. During their training to 2 vs 3 violet squares, the ants of colony E were sufficiently numerous at any time all around these two cues to see and memorize them. Tested in front of 2 and 3 green squares after successively 7, 24, 31 and 48 training hours, the ants went mostly to the 2 green squares (Table 1, line 5), and presented a conditioning score of $69.8 \%, 75.4 \%, 85.1 \%$, and $77.2 \%$ respectively, the counts corresponding to all these scores being significant ( $\mathrm{P}$ $=0.031$ ). Over their 48 training hours, the ants of colony E reached an average conditioning score of $73.9 \%$. While being trained to $3 v s 4$ violet squares, the ants of colony $\mathrm{F}$ were rather numerous at any time all around these two cues, what allowed them seeing and memorizing the two cues. Tested faced with 3 and 4 green squares after successively 7, 24, 31, and 48 training hours, these ants reacted essentially to the 3 green squares (Table 1, line 6 ), presenting a conditioning score of $68.3 \%, 70.0 \%, 73.5 \%$, and $70.7 \%$ respectively. The counts corresponding to these four scores were statistically significant $(\mathrm{P}=0.031)$. The ants' average conditioning score over 48 training hours equaled $70.8 \%$. Thus, the ants of colonies D, E and F respectively duly distinguished 1 from 2, 2 from 3 , and 3 from 4 squares whatever their color.

Table 1. Ants' discrimination of numbers of visual elements when those used for testing differed by one of their characteristics from those used for training

\begin{tabular}{|c|c|c|c|c|c|c|c|c|}
\hline \multirow[t]{2}{*}{ Colony } & \multirow{2}{*}{$\begin{array}{c}\text { Characteristic changed } \\
\text { between training and } \\
\text { testing }\end{array}$} & \multicolumn{2}{|c|}{ Training: $\mathrm{n}^{\circ}$ of elements set } & \multicolumn{4}{|c|}{$\begin{array}{l}\text { Testing: } \mathrm{n}^{\circ} \text { of ants counted near the 'correct' } \\
\text { cue / the 'wrong' cue }\end{array}$} & \multirow{2}{*}{$\begin{array}{l}\text { Average \% of } \\
\text { correct } \\
\text { responses } \\
\end{array}$} \\
\hline & & & & after $7 \mathrm{hrs}$ & $24 \mathrm{hrs}$ & $31 \mathrm{hrs}$ & $48 \mathrm{hrs}$ & \\
\hline A & shape & 1 & 2 & $40 / 19$ & $63 / 16$ & $57 / 20$ & $45 / 10$ & $77.3 \%$ \\
\hline B & shape & 2 & 3 & $56 / 24$ & $53 / 13$ & $62 / 28$ & $46 / 12$ & $73.8 \%$ \\
\hline $\mathrm{C}$ & shape & 3 & 4 & $32 / 15$ & $53 / 21$ & $59 / 26$ & $59 / 21$ & $70.9 \%$ \\
\hline $\mathrm{D}$ & color & 1 & 2 & $46 / 19$ & $52 / 17$ & $57 / 10$ & $51 / 15$ & $77.2 \%$ \\
\hline $\mathrm{E}$ & color & 2 & 3 & $81 / 35$ & $73 / 30$ & $49 / 13$ & $57 / 26$ & $73.9 \%$ \\
\hline $\mathrm{F}$ & color & 3 & 4 & $41 / 19$ & $49 / 21$ & $61 / 22$ & $58 / 24$ & $70.8 \%$ \\
\hline G & size & 1 & 2 & $40 / 17$ & $44 / 15$ & $62 / 19$ & $55 / 16$ & $75.0 \%$ \\
\hline $\mathrm{H}$ & size & 2 & 3 & $37 / 11$ & $46 / 19$ & $44 / 11$ & $37 / 21$ & $72.2 \%$ \\
\hline I & size & 3 & 4 & $34 / 17$ & $79 / 37$ & $39 / 18$ & $29 / 13$ & $68.0 \%$ \\
\hline $\mathrm{J}$ & position & 1 & 2 & $53 / 23$ & $49 / 20$ & $57 / 16$ & $47 / 20$ & $72.3 \%$ \\
\hline K & position & 2 & 3 & $46 / 21$ & $46 / 23$ & $41 / 11$ & $47 / 22$ & $70.6 \%$ \\
\hline $\mathrm{L}$ & position & 3 & 4 & $61 / 34$ & $47 / 18$ & $59 / 28$ & $58 / 31$ & $66.2 \%$ \\
\hline
\end{tabular}

The correct cue was that corresponding to the number of elements located near the food during training (Figure 2). The ants could discriminate the presented elements: all the scores were higher than $50 \%$. However, when the cues used for training and testing were identical, the ants' discrimination between 1 and 2 elements had a mean score of $81.9 \%$ (see the sub section 3.5). The ants' counting is thus influenced mostly by the relative position of the elements to count, somewhat by their size, and slightly by their shape or their color. Details on the methods, results and statistics are given in the text and in the Appendix; photos of the experiments are shown in Figure 3. 


\subsection{Discrimination of Numbers of Elements Whatever Their Size}

While being trained to 1 vs 2 small black squares, the ants of colony $\mathrm{G}$ were sufficiently numerous at any time all around these two cues for seeing and memorizing them. Tested in front of 1 and 2 large squares after 7, 24, 31, and 48 training hours, these ants went essentially to the 1 large square (Table 1, line 7). They reached a conditioning score of $70.2 \%, 75.4 \%, 85.1 \%$, and $77.2 \%$ respectively, the counts corresponding to these scores being statistically significant $(\mathrm{P}=0.031)$. The average ants' conditioning score over their 48 training hours equaled $75.0 \%$. During their training to 2 vs 3 small black squares, the ants of colony $\mathrm{H}$ were very numerous all around these two cues and could thus perceive and memorize them. Tested faced with 2 and 3 large squares after 7, 24, 31, and 48 training hours successively, these ants reacted mostly to the 2 large squares, presenting a conditioning score of $75.5 \%$, $70.8 \%, 80.0 \%$, and $63.8 \%$ respectively (Table 1 , line 8 ). The counts corresponding to these scores were significant $(\mathrm{P}=0.031)$. Calculated over the entire training time, the ants' average conditioning score equaled $72.2 \%$. While being trained to $3 v s 4$ small squares, the ants of colony I were very numerous all around these two cues and thus able to see and memorize them. Tested in front of 3 and 4 large squares after 7, 24, 31, and 48 training hours successively, these ants went mostly towards the 3 squares, presenting a conditioning score of $66.7 \%, 68.1 \%$, $68.4 \%$, and $69.0 \% \%$ respectively (Table 1 , line 9 ). The counts corresponding to each of these scores were significant $(\mathrm{P}=0.31)$. The ants' average conditioning score calculated using the numbers of ants counted during the four testing sessions equaled $68.0 \%$. Consequently, the ants of respectively colonies $\mathrm{G}, \mathrm{H}$, and I correctly distinguished 1 from 2, 2 from 3, and 3 from 4 elements, independently of the smaller or the larger size of these elements.

\subsection{Discrimination of Numbers of Elements Whatever Their Relative Position}

During their training to $1 v s 2$ black squares, the ants of colony $\mathrm{J}$ were numerous enough at any time all around these two cues to memorize them. Tested in front of 1 and 2 black squares otherwise located than during training after 7, 24, 31 and 48 training hours successively, these ants went mostly to the 1 square (Table 1, line 10), presenting a conditioning score of $69.7 \%, 71.0 \%, 78.1 \%$ and $70.1 \%$ respectively. The counts corresponding to these scores were statistically significant $(\mathrm{P}=0.031)$. Over their 48 training hours, the ants of colony $\mathrm{J}$ had an average conditioning score of $72.3 \%$. While being trained to 2 vs 3 black squares, the ants of colony $\mathrm{K}$ were sufficiently numerous all around these two cues for seeing and memorizing them. Tested faced with 2 and 3 black squares otherwise located than during training, after successively 7, 24, 31, and 48 training hours, these ants went mostly to the 2 squares (Table 1, line 11), and presented a conditioning score of $68.7 \%, 66.7 \%, 78.8 \%$, and $68.1 \%$ respectively. The counts corresponding to these scores were significant $(P=0.031)$. The ants' average conditioning score calculated on the basis of the four testing sessions equaled $70.6 \%$. During their training to $3 v s$ 4 black squares, the ants of colony L were numerous enough at any time in the vicinity of these two cues to see and memorize them. Tested in front of 2 and 3 black squares otherwise located than during training, after successively 7, 24, 31, and 48 training hours, these ants went essentially towards the 3 squares (Table 1, line 12), presenting successively a conditioning score of $64.2 \%, 72.3 \%, 67.8 \%$, and $65.2 \%$. The counts corresponding to these scores were statistically significant $(\mathrm{P}=0.031)$. The ants' average conditioning score calculated over the four testing sessions equaled $66.2 \%$. Consequently, the ants of colonies $\mathrm{J}, \mathrm{K}$, and $\mathrm{L}$ duly discriminated 1 from 2, 2 from 3, and 3 from 4 elements respectively, even if those presented during testing were somewhat otherwise positioned than those presented during training.

\subsection{Effect of Shape, Color, Size and Relative Position of Elements on Their Counting}

The ants duly and statistically significantly distinguished the presented numbers of elements even if changes in their shape, color, size and relative position were brought for testing (as ascertained by Wilcoxon tests after each of the four training times).

However, the discrimination accuracy observed in the present work was somewhat lower than that obtained in previous works on the same species when the cues were unchanged between training and testing. More precisely, during a study on the notion of zero, a mean conditioning score of $78.1 \%$ was obtained for the ants' discrimination between 1 and 2 circles, after 48 training hours (Cammaerts \& Cammaerts, 2019a, Table 1). In a study on the ants' correct location of the zero (Cammaerts \& Cammaerts, 2019d), after two training days, these insects presented a conditioning score of $83.3 \%$ (meanly $4.0 v s 0.8$ ants) when asked to learn 2 vs 1 elements, and a score of $82.6 \%$ (meanly 3.8 vs 0.8 ants) when asked to learn 1 vs 2 elements. In a study on the ants' representation of numbers on their number line (Cammaerts \& Cammaerts, 2020), a mean conditioning score of $83.4 \%$ was observed for the ants' discrimination of 1 vs 2 elements, for a training period up to 48 hours. All these proportions are in agreement with one another, their average being $81.9 \%$. This is higher than the values here obtained for the discrimination 
accuracy between 1 and 2 elements $(77.3 \%, 77.2 \%, 75.0 \%$ and $72.3 \%$ : Table 1$)$ when respectively the shape, the color, the size and the relative position of these elements differed between training and testing.
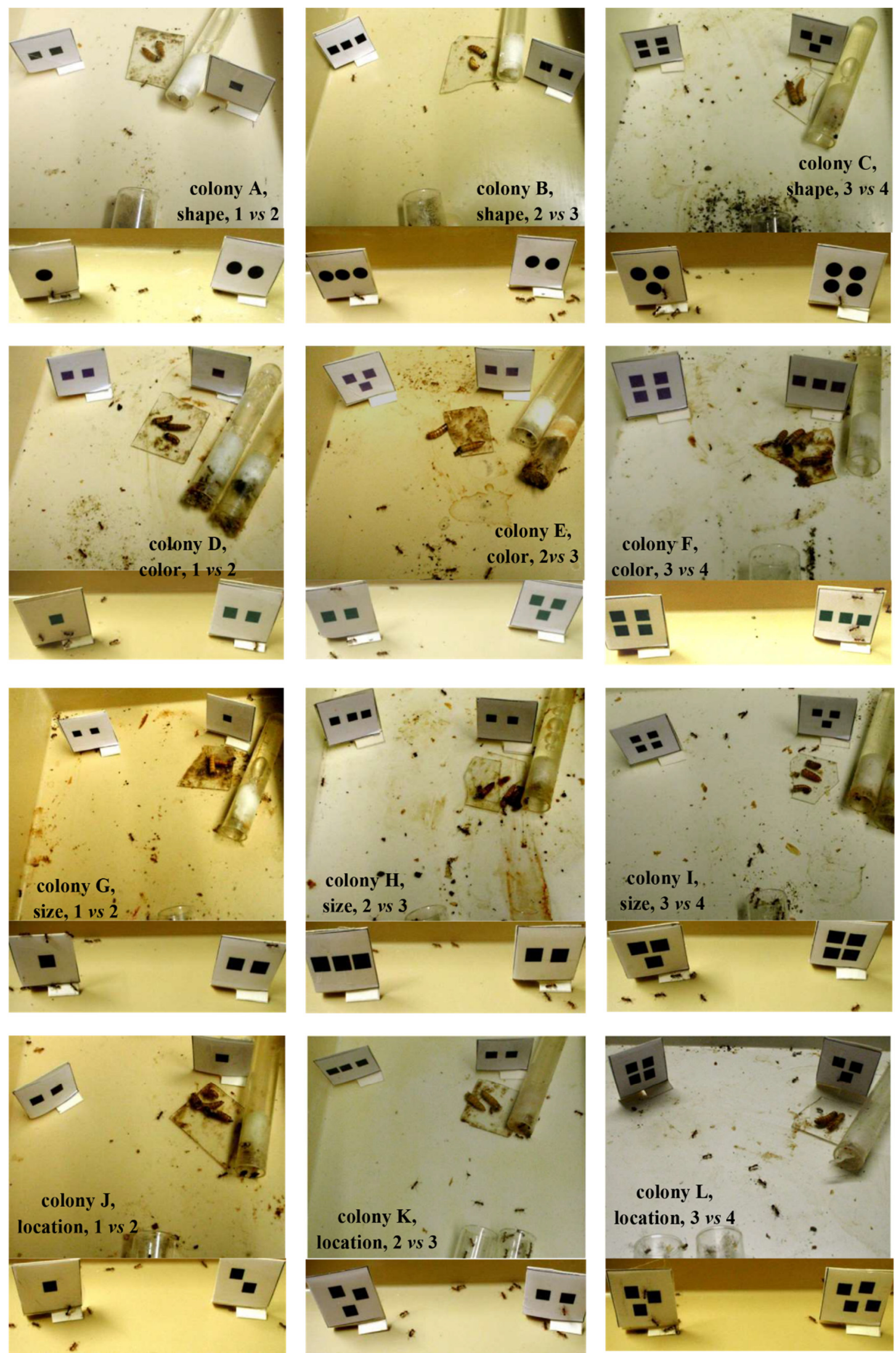
Figure 3. Views of the experiments made to know if ants can recognize 1 to 4 elements even if those seen during testing differ from those seen during training by their shape, color, size, or location

For each colony, the upper photo concerns the ants' training, and the lower one concerns the ants' testing. Details (methods, results, and statistics) are given in the text and the Appendix; numerical results are given in Table 1. Briefly, the ants correctly counted the elements one characteristic of which had been changed. They were only slightly influenced by a change of shape or color of these elements, somewhat by a change of their size, and rather more by a change in their relative position. Such a behavior has ecological and physiological explanations, and may be useful to the ants while foraging or navigating.

Coming back to the present work, the proportion of correct responses varied according to the kind of change made after training (Table 1), the choice being the more correct when the shape or the color was changed, somewhat lesser correct when the size was changed and the less correct when the relative position of the elements was changed. Nevertheless, there was statistically no significant difference between the number of tested ants having chosen the correct or the wrong number of elements faced to either 1 vs 2, 2 vs 3 or 3 vs 4 elements, according to a change in shape, color, size or position of the elements and after training times of either 7, 24, 31 or 48 hours $\left(\chi^{2}\right.$ tests: all results with $\mathrm{P}>0.30$ ). The same conclusion holds when the comparison involved only the changes leading to the most extreme differences (change of shape and change of relative position: $\chi^{2}$ tests: all results with $P>0.20$ ). There was also no statistical difference when Fisher tests were used on the number of ants sighted during only the first two minutes of their counting (all results with $\mathrm{P}$ (two-tailed) $>0.25$ ).

The impact of each of these four changes on the species' counting ability is commented in the Discussion section.

Incidentally, a decrease of the ants' scores when discriminating between increasing number of elements must be noted. This can be accounted for a size effect, i.e. the fact that discrimination becomes harder when numbers or physical stimuli increase in magnitude (Cammaerts \& Cammaerts, 2020).

\section{Discussion - Conclusion}

Having previously shown that the workers of the ant $M$. sabuleti can distinguish different numbers of elements, however by using cues differing only by the numbers of their elements during training and testing, we here examined if these ants can also distinguish two different numbers of elements when these elements differed by their shape, color, size or location between training and testing. Using operant conditioning, we found that the workers of the ant $M$. sabuleti correctly discriminated 1 from 2, 2 from 3 and 3 from 4 elements (squares or circles), and thus counted the numbers of these elements, even when those presented during testing differed by their shape, their color, their size or their location from those presented during training. We can thus conclude that the ants duly distinguish small numbers of sighted elements.

Nevertheless, the ants' counting or discriminating ability is not fully independent of the characteristics of the elements to count, even for numbers 1 to 4 . Indeed, the ants' ability in counting 1 and 2 elements observed in the present work was somewhat lower than those observed in previous works during which the characteristics of the elements to count were identical between training and testing. For the discrimination between 1 and 2 elements, we previously obtained a mean conditioning score of $81.9 \%$ (see sub section 3.5), while in the present work we observed a conditioning score of $77.3 \%, 77.2 \%, 75.0 \%$ and $72.3 \%$ when respectively the shape, color, size and relative position of the elements to count differed between training and testing. The location of the elements had the highest impact on the ants' counting, followed by the size and, to a lesser extent by the shape and color of these elements. Such an impact can be explained by characteristics of the visual perception of the species and by its ecology and may thus have a meaning for its life in the wild. Indeed, Myrmica sabuleti is the most active during the night and even if, to some extent, colors can be still discriminated by foragers during the dark period of the day (Cammaerts, 2007; M.-C. Cammaerts \& D. Cammaerts, 2009), they are not particularly important for navigating during that time period. Moreover, M. sabuleti workers have a visual perception of poor quality, with a large subtended angle of vision (Cammaerts, 2004). They distinguish squares and circles with difficulties (as well as rectangles and ellipses) (Cammaerts, 2008). Therefore, for them, a small change of shape does not seriously affect what they visually perceive. On the contrary, a change of size and above all of the relative position of sighted elements may be important for these ants, and are thus likely to impact their counting ability. Finally, in the wild, the characteristics (shape, color, size, position) of encountered elements (prey, sugar food, cues useful to navigate) are probably as important as their numbers for correctly navigating to the nest, to food sites, and for foraging all around. 
This is valid for numbers 1 to 4 , the ants probably subitizing these small numbers instead of effectively counting them. Faced with larger numbers of elements, the ants could perhaps be more largely influenced by the physical characteristics of the encountered elements.

We cannot compare the present observations and conclusions (i.e. the ants duly count elements even if characteristics of these elements somewhat change, but do so then less well) to those of studies on other animal species for which several features of the cues were changed at the same time, the aim of these other works having been to control number discrimination, not to analyze the effect of each extraneous feature on the animal numerosity ability. We can only advance that the ants' counting or number discrimination can be somewhat impacted by co-varying features of the elements to count, and that, ranked according to the importance of their impact, the relative position, then the size, and finally equally the color and the shape affect the ants' counting.

For introducing the present work, we reported some studies which showed that animals can count, although the numbers of elements that were displayed during testing had not the same characteristics as those presented during training. Here below, we discuss about other works on the subject.

The work of Gross et al. (2009) on honeybees obviously experimentally proved that these insects truly counted numbers of elements independently of their color, configuration, area, perimeter or the illusory contours they formed. However, this counting ability had a limit: bees could apply their learning of distinguishing 2 from 3 to that of 3 from 4, but not to that of 4 from 5 and 5 from 6. In another work (Bortot et al., 2019), bees were found to effectively count numbers of elements (black circles) (using absolute rather than relative numerosity in their number discrimination) whatever the size and pattern of these dots, the correct number being the smaller or the larger one, and could apply this learning to other pairs of numbers of elements. However, the latter ability was significant for 2 vs 3 and 3 vs 2 but not for 3 vs 4 and 4 vs 3 . The bees' true counting ability may thus be limited to 4 items, such as that of M. sabuleti when at least one feature of the elements to count differs between training and testing.

During their experiments on elephants, Irie et al. (2019) showed that an elephant could count, or at least subitize, two different amounts of elements (pictures of fruits), doing so without being affected by the numerical distance and size of the presented amounts or by their ratio. However, this finding was obtained with only one individual with a proportion of correct responses of $66.8 \%$, a performance of a somewhat low level.

Even if their aim was not to examine the effect of co-variants of the elements to be counted (their aim was to check if Weber's law could be applied), Jordan and Brannon (2006) revealed that rhesus monkeys truly count items (cues of different size, color, density and displayed pattern) independently of their non-numerical characteristics. In the same way, but experimenting on crows (Corvus corone) with the aim of looking if Weber's law could be applied to these birds' counting ability, Ditz and Nieder (2016) pointed out at the same time that these crows correctly count elements, responding even if the elements presented during testing differed by their size and display from those used for training. Although in the present work on the ant M. sabuleti, extraneous features were not controlled as much as in the above-cited experimental works, our results nevertheless show that workers of this ant can count even if some characteristics of the elements to be counted are changed between training and testing. Tomonaga (2006) experimented on chimpanzees and while proving that they duly count elements in line with Weber's law, he showed that pattern characteristics of the dot display somewhat influenced the monkeys' counting ability though these monkeys still significantly perceived the difference between the number of dots. This result recalls what we found on ants.

As a conclusion, we can advance that workers of the ant $M$. sabuleti are able to make true counting and discrimination of small numbers of elements, this ability being to some extent affected by changes in relative position (essentially), size (to a lower extend), color and shape (to the lesser extend) of the elements to count. The effects of these extraneous variables may be explained by the visual perception accuracy, the navigation requirement and the ecology of the species.

\section{Acknowledgement}

We thank an anonymous referee for suggestions which allowed improving the readability of our paper.

\section{References}

Agrillo, C., Dadda, M., Serena, G., \& Bisazza, A. (2009). Use of number by fish. PLoS ONE, 4(3), e4786. doi: 10.1371/journal.pone.0004786

Bortot, M., Agrillo, C., Avarguès-Weber, A., Bisazza, A., Miletto Petrazzini, M. E., \& Giurfa, M. (2019). Honeybees use absolute rather than relative numerosity in number discrimination. Biology Letters, 15, 20190138. doi: 10.1098/rsbl.2019.0138 
Brannon, E. M., \& Terrace, H. S. (1998). Ordering of the numerosities 1 to 9 by monkeys. Science, 282, 746-749. doi: $10.1126 /$ science.282.5389.746

Brannon, E. M., \& Terrace, H. S. (2000). Representation of the numerosities 1-9 by rhesus macaques (Macaca mulatta). Journal of Experimental Psychology: Animal Behavior Processes, 26(1), 31-49. doi: 10.1037/0097-7403.26.1.31

Cammaerts, M.-C. (2004). Some characteristics of the visual perception of the ant Myrmica sabuleti. Physiological Entomology, 29, 472-482. doi: 10.1111/j.0307-6962.2004.00419.x

Cammaerts, M.-C. (2007). Colour vision in the ant Myrmica sabuleti Meinert, 1861 (Hymenoptera: Formicidae). Myrmecological News, 10, 41-50.

Cammaerts, M.-C. (2008). Visual discrimination of cues differing as for their number of elements, their shape or their orientation, by the ant Myrmica sabuleti. Biologia, 63, 1169-1180. doi: 10.2478/s11756-008-0172-2

Cammaerts, M.-C., \& Cammaerts, D. (2009). Light thresholds for colour vision in the workers of the ant Myrmica sabuleti (Hymenoptera: Formicidae). Belgian Journal of Zoology, 138, 40-49.

Cammaerts, M.-C., \& Cammaerts, R. (2019a). Ants are at the first stage of the notion of zero. International Journal of Biology, 11(1), 54-65. doi: 10.5539/ijb.v11n1p54

Cammaerts, M.-C., \& Cammaerts, R. (2019b). Ants' capability of adding numbers of identical elements. International Journal of Biology, 11(3), 25-36. doi: 10.5539/ijb.v11n3p25

Cammaerts, M.-C., \& Cammaerts, R. (2019c). Ants fail to add numbers of same elements seen consecutively. International Journal of Biology, 11(3), 37-48. doi: 10.5539/ijb.v11n3p37

Cammaerts, M.-C., \& Cammaerts, R. (2019d). Ants correctly locate the zero in a continuous series of numbers. International Journal of Biology, 11(4), 16-25. doi: 10.5539/ijb.v11n4p16

Cammaerts, M.-C., \& Cammaerts, R. (2019e). Subtraction-like effect in an ant faced with numbers of elements which includes a crossed one. International Journal of Biology, 11(4), 51-66. doi: 10.5539/ijb.v11n4p51

Cammaerts, R., \& Cammaerts, M.-C. (2020). Ants' mental positioning of amounts on a number line. International Journal of Biology, 12(1), 30-45. doi: 10.5539/ijb.v12n1p30

Cantlon, J. F., \& Brannon, E. M. (2006). Shared system for ordering small and large numbers in monkeys and humans. Psychological Science, 17(5), 401-406. doi: 10.1111/j.1467-9280.2006.01719.x

Ditz, H. M., \& Nieder, A. (2015). Neurons selective to the number of visual items in the corvid songbird endbrain. PNAS, 112(25), 7827-7832. doi: 10.1073/pnas.1504245112

Ditz, H. M., \& Nieder, A. (2016). Numerosity representations in crows obey the Weber-Fechner law. Proceedings of the Royal Society of London B, 283, 1-9. doi: 10.1098/rspb.2016.0083

Emmerton, J., \& Renner, J. C. (2006). Scalar effects in the visual discrimination of numerosity by pigeons. Learning \& Behavior, 34(2), 176-192. doi: 10.3758/BF03193193

Flombaum, J. I., Junge, J. A., \& Hauser, M. D. (2005). Rhesus monkeys (Macaca mulatta) spontaneously compute addition operations over large numbers. Cognition, 97, 315-325. doi: 10.1016/j.cognition.2004.09.004

Gazes, R. P., Diamond, R. F. L., Hope, J. M., Caillaud, D., Stoinski, T. S., \& Hampton, R. R. (2017). Spatial representation of magnitude in gorillas and orangutans. Cognition, 168, 312-319. doi: 10.1016/j.cognition.2017.07.010

Gross, H. J., Pahl, M., Si, A., Zhu, H., Tautz, J., \& Zhang, S. (2009). Number-based visual generalisation in the honeybee. PLoS ONE, 4(1), e4263. doi: 10.1371/journal.pone.0004263

Howard, S. R., Avarguès-Weber, A., Garcia, J. E., Greentree, A. D., \& Dyer, A. G. (2019). Numerical cognition in honeybees enables addition and subtraction. Cognitive Neuroscience, 5, 1-6. doi: 10.1126/sciadv.aav0961

Irie, N., Hiraiwa-Hasegawa, M., \& Kutsukake, N. (2019). Unique numerical competence of Asian elephants on the relative numerosity judgment task. Journal of Ethology, 37, 111-115. doi: 10.1007/s10164-018-0563-y

Jordan, K. E., \& Brannon, E. M. (2006). Weber's law influences numerical representations in rhesus macaques (Macaca mulatta). Animal Cognition, 9, 159-172. doi: 10.1007/s10071-006-0017-8

Merritt, D. J., \& Brannon, E. M. (2013). Nothing to it: Precursors to a zero concept in preschoolers. Behavioural Processes, 93, 91-97. doi: 10.1016/j.beproc.2012.11.001 
Merten, K., \& Nieder, A. (2008). Compressed scaling of abstract numerosity representations in adult humans and monkeys. Journal of Cognitive Neuroscience, 21(2), 333-346. doi: 10.1162/jocn.2008.21032

Nieder, A., Freedman, D. J., \& Miller, E. K. (2002). Representation of the quantity of visual items in the primate prefrontal cortex. Science, 297, 1708-1711. doi: 10.1126/science.1072493

Okuyama, S., Kuki, T., \& Mushiake, H. (2015). Representation of the numerosity 'zero' in the parietal cortex of the monkey. Scientific Reports, 5, 10059. doi: 10.1038/srep10059

Pepperberg, I. M. (2012). Further evidence for addition and numerical competence by a grey parrot (Psittacus erithacus). Animal Cognition, 15(4), 711-717. doi: 10.1007/s10071-012-0470-5

Range, F., Jenikejew, J., Schröder, I., \& Virányi, Z. (2014). Difference in quantity discrimination in dogs and wolves. Frontiers in Psychology, 5, 1299. doi: 10.3389/fpsyg.2014.01299

Rodríguez, R. L., Briceño, R. D., Briceño-Aguilar, E., \& Höbel, G. (2015). Nephila clavipes spiders (Araneae: Nephilidae) keep track of captures prey counts: Testing for a sense of numerosity in an orb-weaver. Animal Cognition, 18(1), 307-314. doi: 10.1007/s10071-014-0801-9

Rugani, R., \& de Hevia, M.-D. (2017). Number-space associations without language: Evidence from preverbal human infants and non-human animal species. Psychonomic Bulletin \& Review, 24, 352-369. doi: 10.3758/s13423-016-1126-2

Siegel, S., \& Castellan, N. J. (1989). Nonparametric statistics for the behavioural sciences. Singapore, McGraw-Hill Book Company. Retrieved from https://www.amazon.com/Sidney-Siegel...Statistics.../B008W DIR6

Tomonaga, M. (2006). Relative numerosity discrimination by chimpanzees (Pan troglodytes): Evidence for approximate numerical representations. Animal Cognition, 11, 43-57. doi: 10.1007/s10071-007-0089-0

Xu, F., \& Spelke, E. S. (2000). Large number discrimination in 6-month-old infants. Cognition, 74, B1-B11. doi: 10.1016/S0010-0277(99)00066-9

\section{Appendix}

Here, we detail the numerical and statistical results obtained in the course of the twelve conducted experiments and briefly related in the subsection 'Results' under the subtitles here repeated.

\subsection{Discrimination of Numbers Whatever Their Shape}

Trained to 1 black square set near the food $v s 2$ black squares set far from the food, the ants of colony A were meanly 3.5 on this area. Tested after 7 training hours in front of 1 and 2 black circles, these ants already went somewhat more to the 1 black circle than to the 2 black circles (40 vs 19). Their proportion of correct responses equaled $67.8 \%$. Summed by four, the numbers of ants sighted near 1 black circle were $7,6,12,11,4$, and sighted near the 2 circles they were $1,4,7,5,2$. These two series statistically differed $(\mathrm{N}=5, \mathrm{~T}=15, \mathrm{P}=0.031)$. After 24 training hours, the ants went promptly to the 1 black circle, and less to the 2 black circles (63vs 16), presenting thus a conditioning score of $78.7 \%$. Summed by four over the twenty counts, the numbers of ants counted near the 1 circle were $11,14,7,18,13$, and counted near the 2 circles they were $2,4,4,3,3$. These two series of values significantly differed $(\mathrm{N}=5, \mathrm{~T}=15, \mathrm{P}=0.031)$. After 31 training hours, the ants went again essentially to the 1 circle but not as promptly as previously ( $57 \mathrm{vs} 20$ ), presenting then a conditioning score of $74.0 \%$. Summed by four, the numbers of ants sighted near the 1 circle were $10,9,12,13,13$, and those sighted near the two circles were 4, 3 , $5,4,4$. The two obtained series statistically differed $(\mathrm{N}=5, \mathrm{~T}=15, \mathrm{P}=0.031)$. After a total of 48 training hours, the ants went more promptly to the 1 circle than previously ( $45 v s 10$ ), reaching a final conditioning score of $81.8 \%$. Summed by four over the twenty counts, the numbers of ants approaching the 1 circle were $8,9,9,8,11$, and of those approaching the 2 circles, $2,3,2,2,1$. These two series statistically differed $(\mathrm{N}=5, \mathrm{~T}=15, \mathrm{P}=0.031)$. The ants' average conditioning score calculated on the basis of the four assessments made over their total training time equaled $77.3 \%$. We can thus conclude that the ants very well distinguished the 1 circle from the 2 circles, counting therefore 1 and 2 elements, even if those presented during testing had a different shape than those presented during training.

During their training to 2 black squares set near the food $v s 3$ black squares set far from food, the ants of colony B were meanly 3.8 at any time on this area. Tested after 7 training hours, these ants already reacted essentially to the 2 circles, 56 ants having been counted near that cue and 24 ones near the other cue. The ants presented thus a conditioning score of $70 \%$. Summed by four over the twenty counts, the numbers of ants sighted in front of the 2 
circles were $10,11,11,12,12$, and sighted in front of the 3 circles they were $3,4,5,8,4$. These two series significantly differed $(\mathrm{N}=5, \mathrm{~T}=15, \mathrm{P}=0.031)$. After 24 training hours, the ants promptly went more to the 2 circles than to the 3 circles ( 53 vs 13), and presented thus a conditioning score of $80.3 \%$. Summed by four, the numbers of ants counted near the 2 circles were $7,10,12,10,14$, and those counted near the 3 circles were $2,4,4$, 0,3 . These two series statistically differed $(\mathrm{N}=5, \mathrm{~T}=15, \mathrm{P}=0.031)$. After having been trained for 31 hours, the ants again went essentially to the 2 circles, but less than during the previous test: they were 62 in doing so while 28 ants went to the 3 circles. Their conditioning score equaled thus $68.9 \%$. Summed by four, the numbers of ants which moved to the 2 circles were $10,11,14,11,16$, and which moved to the 3 circles, $6,4,4,8,6$. These two series significantly differed $(\mathrm{N}=5, \mathrm{~T}=15, \mathrm{~T}=0.031)$. After a total of 48 training hours, the ants went again promptly to the 2 circles and less to the 3 ones (46 vs 12). Their conditioning score equaled then $79.3 \%$. Summed by four, the numbers of ants which reacted to the 2 circles were $6,11,9,9,11$, and those of ants which reacted to the 3 circles were $1,4,3,2,2$. These two series statistically differed $(\mathrm{N}=5, \mathrm{~T}=15, \mathrm{P}=0.031)$. At the end of the experiment, the average ants' conditioning score appeared to equal $73.8 \%$. It can thus be concluded that the ants distinguished 2 circles from 3 circles, counted these two numbers of elements, even if those presented during testing had a different shape than those presented during training.

While being trained to 3 black squares set near the food $v s 4$ such squares set far from the food, the ants of colony C were meanly 3.8 there at any time. After 7 training hours, these ants went mostly to the 3 circles, 32 ants having been counted there and 15 ones near the 4 circles. The ants presented thus at that time a conditioning score of $68.1 \%$. Summed by four over the twenty counts, the numbers of ants sighted near the 3 circles were $6,6,6,5,9$, and those sighted near the 4 circles were $2,3,3,2,5$. These two series of values significantly differed $(\mathrm{N}=5, \mathrm{~T}=$ $15, \mathrm{P}=0.031$ ). The ants reacted more obviously essentially to the 3 circles after 24 training hours: they were 53 in going towards that cue and 21 ones in going to the 4 circles. They reached thus a conditioning score of $71.6 \%$. Summed by four over the twenty counts, the numbers of ants sighted near the 3 circles were $6,15,9,14$, 9 , and sighted near the 4 circles they were $2,6,4,6,3$. These two series significantly differed $(\mathrm{N}=5, \mathrm{~T}=15, \mathrm{P}=0.031)$. After 31 training hours, the ants went on reacting mostly to the 3 circles (59vs 26 reacting to the 4 circles), and presented thus a conditioning score of $69.4 \%$. Summed by four, the numbers of ants which approached the 3 circles were $12,10,11,11,15$, and those of ants which approached the 4 circles were $5,5,6,5,5$. These two series significantly differed $(\mathrm{N}=5, \mathrm{~T}=15, \mathrm{P}=0.031)$. After a total of 48 training hours, the ants again went essentially to the 3 circles, being 59 in doing so while 21 ants went to the 4 circles. The ants' conditioning score equaled thus at that time $73.8 \%$. Summed by four, the numbers of ants sighted in front of the 3 circles were $7,8,12,17,15$, and those sighted in front of the 4 circles were $1,3,6,6,5$. These two series statistically differed $(\mathrm{N}=5, \mathrm{~T}=15, \mathrm{P}=$ 0.031). The ants' average conditioning score obtained over their total training time equaled $70.9 \%$. We can thus conclude that the ants distinguished 3 elements from 4 elements and duly counted them independently of their shape.

\subsection{Discrimination of Numbers Whatever Their Color}

While being trained to 1 violet square set near the food versus 2 such squares set far from the food, the ants of colony D were meanly 6.4 at any time all around these two cues. Tested after 7 training hours, these ants went more to the 1 presented green square than to the 2 green squares, 46 ants having approached the 1 green square and 19 ants having approached the 2 squares. The ants' conditioning equaled thus at that time $70.8 \%$. Summed by four, the numbers of ants counted near the 1 green square were $11,12,8,7,8$ and those counted in front of the 2 green squares were $3,6,2,2,6$. These two series significantly differed $(\mathrm{N}=5, \mathrm{~T}=15, \mathrm{P}=0.031)$. After 24 training hours, the ants' moving towards the 1 green square was more obvious, 52 ants having been counted near that cue and 19 ones near the 2 green squares. The ants' conditioning score equaled thus at that time $75.4 \%$. Summed by four, the numbers of ants sighted near the 1 square were $15,10,9,9,9$, and sighted near the 2 squares they were 2, 4, 4, 4, 3 . These two series statistically differed $(\mathrm{N}=5, \mathrm{~T}=15, \mathrm{P}=0.031)$. After 31 training hours, the ants still more approached essentially the 1 green square: they were 57 in doing so and only 10 in approaching the 2 squares. The ants' conditioning score was thus of $85.1 \%$. Summed by four, the numbers of ants reacting to 1 square were $7,8,10$, 15,17 , and reacting to 2 squares they were $2,0,2,3,3$. The two series once more significantly differed $(\mathrm{N}=5, \mathrm{~T}=$ $15, \mathrm{P}=0.031$ ). After a total of 48 hours, the ants went again, though less obviously, mostly to the 1 square, being 51 in doing so while 15 ones went to the 2 squares. The ants presented then a conditioning score of $77.2 \%$. Summed by four over the twenty counts, the numbers of ants having approached the 1 square were $10,12,10,8,11$, and those having approached the 2 squares were $3,4,2,3,3$. These two series significantly differed $(\mathrm{N}=5, \mathrm{~T}=15$, $\mathrm{P}=0.031$ ). The ants' average conditioning score over their 48 training hours equaled $77.2 \%$. The ants have thus distinguished 1 from 2 elements independently of the color of these elements. 
During their training to 2 violet squares versus 3 such squares, the ants of colony E were rather numerous at any time all around these two cues (they were meanly 7.1). As soon as after 7 training hours, these ants went somewhat mostly to the 2 green squares: 81 ants were sighted in front of that cue and 35 ones in front of the other cue, the ants conditioning score equaling thus $69.8 \%$. Summed by four, the numbers of ants counted near the 2 green squares were $17,22,14,14,14$, and near the 3 green squares, they were $7,12,5,6,5$. These two series statistically differed $(\mathrm{N}=5, \mathrm{~T}=15, \mathrm{P}=0.031)$. After 24 training hours, the ants similarly went mostly to the 2 green squares, 73 ants having been counted there and 30 ones near the other cue. The ants' conditioning score equaled thus $70.9 \%$ at that time. Summed by four, the numbers of ants reacting to the 2 squares were 22, 16, 12, 14, 9, and those of ants reacting to the 3 squares were $10,6,5,4,5$, these two series statistically differing $(\mathrm{N}=5, \mathrm{~T}=15, \mathrm{P}=0.031)$. After 31 training hours, the ants went more promptly essentially to the 2 squares: they were 49 in doing so while 13 ones went to the 3 squares. The ants' conditioning score was thus $79.0 \%$. Summed by four, the numbers of ants sighted near the 2 squares were $10,11,8,12,8$, and sighted near the 3 squares they were $2,4,2,2,3$. The two obtained series of values significantly differed $(\mathrm{N}=5, \mathrm{~T}=15, \mathrm{P}=0.031)$. After a total of 48 hours, the ants once more went mostly to the 2 squares, though somewhat less than during the previous test. Being 57 in doing so and 26 in going to the 3 squares, the ants presented a conditioning score of $68.7 \%$. Summed by four over the twenty counts, the numbers of ants approaching the 2 squares were $7,12,13,14,11$, and those of ants approaching the 3 squares were $4,7,6,6,3$. These two series were statistically different $(\mathrm{N}=5, \mathrm{~T}=15, \mathrm{P}=0.031)$. Over their 48 training hours, the ants of colony $\mathrm{E}$ had an average conditioning score of $73.9 \%$. The ants discriminated thus well 2 from 3 elements, whatever their color.

While being training to 3 violet squares versus 4 such squares, the ants of colony F were meanly 4.8 at any time all around these two cues, what was sufficient for seeing and memorizing the two presented squares. Tested after 7 training hours, these ants already went essentially to the 3 green squares: 41 did so while 19 ants went to the 4 green squares, the ants' conditioning score equaling thus $68.3 \%$. Summed by four, the numbers of ants counted near the 3 squares were $8,8,8,9,8$ and counted near the 4 squares, they were $3,4,3,4,5$. These two series statistically differed $(\mathrm{N}=5, \mathrm{~T}=15, \mathrm{P}=0.031)$. After 24 training hours, the ants again went essentially to the 3 green squares, being 49 in doing so while 21 ants went to the 4 circles. The ants presented thus at that time a conditioning score of $70.0 \%$. Summed by four, the numbers of ants sighted near the 3 squares were $10,10,8,10$, 11 , and sighted near the 4 squares they were $3,4,4,5,5$. These two series significantly differed $(N=5, T=15, P$ $=0.031$ ). After 31 training hours, the ants went somewhat mostly to the 3 green squares. They were 61 in doing so while 22 ants went to the 4 squares. The ants had thus then a conditioning score of $73.5 \%$. Summed by four, the numbers of ants which approached the 3 squares were $7,10,14,15,15$, and those which approached the 4 squares were $2,2,4,7,7$. These two series statistically differed $(\mathrm{N}=5, \mathrm{~T}=15, \mathrm{P}=0.031)$. After a total of 48 training hours, the ants went on going essentially towards the 3 squares, being 58 in doing so while 24 ones went to the 4 squares. The ants' conditioning equaled thus $70.7 \%$. Summed by four, the numbers of ants counted in front of the 3 squares were $13,10,11,14,10$, and counted in front of the 4 squares they were $4,4,4,6,6$. Once more, these two series statistically differed $(\mathrm{N}=5, \mathrm{~T}=15, \mathrm{P}=0.031)$. The ants' average conditioning score over their 48 training hours equaled $70.8 \%$. We can thus conclude that the ants duly counted 3 and 4 elements whatever the color (violet or green) of these elements.

\subsection{Discrimination of Numbers Whatever Their Size}

While being trained to 1 small black square set near the food versus 2 such squares set far from the food, the ants of colony $\mathrm{G}$ were rather numerous (meanly 5.0) at any time all around these two cues. Tested after 7 training hours, these ants already went essentially to the 1 large square: they were 40 in doing so while 17 ants went to the 2 large squares. The ants' conditioning score equaled thus then $70.2 \%$. Summed by four, the numbers of ants counted near the 1 square were $6,6,7,9,12$, and counted near the 2 squares they were $1,2,3,5,6$. These two series statistically differed $(\mathrm{N}=5, \mathrm{~T}=15, \mathrm{P}=0.031)$. After 24 training hours, the ants went again essentially to the 1 square being 44 in doing so while 15 ants went to the 2 squares, the ants presenting thus a conditioning score of $74.6 \%$. Summed by four, the numbers of ants sighted near the 1 square were $8,9,9,8,10$, and those of ants sighted near the 2 squares were $2,4,4,2,3$. These two series significantly differed $(\mathrm{N}=5, \mathrm{~T}=15, \mathrm{P}=0.031)$. After having been trained for 31 hours, the ants presented a conditioning score of $76.5 \%$ since 62 ants were counted in front of the 1 square and 19 ones in front of the 2 squares. Summed by four, the numbers of ants reacting to the 1 square were $12,12,13,15$, 10 , and those of ants reacting to the 2 squares were $5,3,3,6,0$. The two series statistically differed $(\mathrm{N}=5, \mathrm{~T}=15$, $\mathrm{P}=0.031$ ). After a total of 48 hours, the ants went on going mostly to the 1 large square; they were 55 in doing so while 16 ones went to the 2 squares. The ants' conditioning score equaled thus $77.5 \%$. Summed by four, the numbers of ants sighted near the 1 square were $7,8,12,10,19$, and sighted near the 2 squares they were $3,3,3,2$, 
5. These two series significantly differed $(\mathrm{N}=5, \mathrm{~T}=15, \mathrm{P}=0.031)$. The average ants' conditioning score over their 48 training hours equaled $75.0 \%$. Thus, the ants duly counted 1 and 2 elements, whatever their size.

During their training to 2 small black squares set near their food versus 3 such squares set far from the food, the ants of colony $\mathrm{H}$ were very numerous all around these two cues. They were indeed meanly 11.0 at any time on this area. After 7 training hours, these ants reacted mostly to the 2 large squares, being 37 in going towards that cue while 11 ones went to the 3 large squares. The ants presented thus a conditioning score of $75.5 \%$. Summed by four over the twenty counts, the numbers of ants sighted near the 2 squares were $4,8,11,8,6$, and sighted near the 3 squares, they were $0,4,3,3,2$. These two series statistically differed $(\mathrm{N}=5, \mathrm{~T}=15, \mathrm{P}=0.031)$. After 24 training hours, the ants again moved essentially to the 2 squares: 46 ones did so and 19 ones went to the 3 squares, the ants presenting thus a conditioning score of $70.8 \%$. Summed by four, the numbers of ants approaching the 2 squares were $7,9,11,9,10$, and of ants approaching the 3 squares were $0,4,5,7,3$. These two series statistically differed $(\mathrm{N}=5, \mathrm{~T}=15, \mathrm{P}=0.031)$. After having been trained for 31 hours, 44 tested ants went to the 2 squares and 11 ones went to the 3 squares, the ants' conditioning score equaling thus $80.0 \%$. Summed by four, the numbers of ants moving to the 2 squares were $9,14,5,8,8$, and of ants moving to the 3 squares were $2,4,1,0,4$. These two series significantly differed $(\mathrm{N}=5, \mathrm{~T}=15, \mathrm{P}=0.031)$. After a total of 48 training hours, the ants went again, though less obviously, to the 2 large squares, 37 ones having been sighted there and 21 ants having been sighted near the 3 squares. The ants' conditioning score equaled at that time $63.8 \%$. Summed by four, the numbers of ants counted near the 2 squares were $7,6,6,10,8$, and those of ants counted near the 3 squares were $3,4,3,8,3$, these two series significantly differing $(\mathrm{N}=5, \mathrm{~T}=15, \mathrm{P}=0.031)$. Calculated over the entire training time, the ants' average conditioning score equaled $72.2 \%$. The ants thus duly discriminated and counted 2 and 3 squares independently of their size.

While being trained to 3 small squares set near the food versus 4 such squares set far from food, the ants of colony I were very numerous all around these two cues (they were meanly 11.8 there at any time). Tested after 7 training hours in front of 3 and 4 large squares, these ants went somewhat mostly towards the 3 squares. Indeed, 34 ants were counted in front of these 3 squares while 17 ones were counted in front of the 4 squares, the ants presenting thus a conditioning score of $66.7 \%$. Summed by four, the numbers of ants sighted near the 3 squares were $4,7,7,7$, 9 , and of ants sighted near the 4 squares were $0,5,4,3,5$. These two series statistically differed $(\mathrm{N}=5, \mathrm{~T}=15, \mathrm{P}$ $=0.031$ ). Tested after 24 training hours, the ants again reacted essentially to the 3 large squares: 79 ants have been counted in front of such squares and 37 ones in front of the 4 squares. The ants' conditioning score equaled thus at that time $68.1 \%$. Summed by four, the numbers of ants sighted near the 3 squares were $8,12,17,21,21$, and sighted near the 4 squares were $2,6,8,10,11$. These two series statistically differed $(\mathrm{N}=5, \mathrm{~T}=15, \mathrm{P}=0.031)$. After 31 training hours, the ants once more went mostly to the 3 squares, being 39 in doing so while 18 ants went to the 4 squares. The ants had thus then a conditioning score of $68.4 \%$. Summed by four, the numbers of ants having approached the 3 squares were 5, 7, 9, 9, 9, and those of ants having approached the 4 squares were 1, 3, 5, 4, 4. The two obtained series significantly differed $(\mathrm{N}=5, \mathrm{~T}=15, \mathrm{P}=0.031)$. After a total of 48 training hours, the ants went on reacting mostly to the 3 large squares, being 29 in doing so while 13 reacted to the 4 squares. They presented thus a conditioning score of $69.0 \%$. Summed by four, the numbers of ants counted near the 3 squares were $6,7,5$, 7,4 , and those of ants counted near the 4 squares were $0,6,3,4,0$. These two series statistically differed $(\mathrm{N}=5, \mathrm{~T}$ $=15, \mathrm{P}=0.031$ ). Over their entire training time, the ants had an average conditioning score of $68.0 \%$. They thus duly counted the 3 and the 4 presented squares even if those seen during testing were larger than those seen during training.

\subsection{Discrimination of Numbers Whatever Their Location}

While being trained to 1 black square set near the food versus 2 such squares set far from the food, the ants of colony J were very numerous around these two cues, being meanly 11.8 there at any time. Tested after 7 training hours in front of 1 and 2 squares otherwise located than during training, these ants went essentially to the 1 square, being 53 in doing so while 23 ants went to the 2 squares. They thus presented a conditioning score of $69.7 \%$. Summed by four over the twenty counts, the numbers of ants sighted near the 1 square were $12,14,9,10,8$, and those of ants sighted near the 2 squares were $5,7,5,5,1$. These two series of five values significantly differed (N $=5, \mathrm{~T}=15, \mathrm{P}=0.031$ ). After 24 training hours, these ants went on approaching essentially the 1 square: they were 49 in doing so while 20 ants approached the 2 squares. The ants presented thus at that time a conditioning score of $71.0 \%$. Summed by four, the numbers of ants having approached the 1 square were $10,12,9,6,12$, and those of ants having approached the 2 squares were $3,5,4,2,6$. The two obtained series of values significantly differed ( $\mathrm{N}$ $=5, \mathrm{~T}=15, \mathrm{P}=0.031$ ). After 31 training hours, the ants more promptly went mostly towards the 1 square: they were 57 in doing so while 16 ants went to the two squares. The ants' conditioning score equaled thus then $78.1 \%$. Summed by four, the numbers of ants counted near the 1 square were $10,11,9,16,11$, and those of ants counted 
near the 2 squares were $1,3,1,7,4$. These two series statistically differed $(\mathrm{N}=5, \mathrm{~T}=15, \mathrm{P}=0.031)$. After having been trained for 48 hours, the ants again went essentially to the 1 square, being 47 in doing so while 20 ants went to the 2 squares. They thus presented a conditioning score of $70.1 \%$. Summed by four, the numbers of ants sighted near the 1 square were $10,10,10,8,9$, and of ants sighted near the 2 squares were $5,6,5,2,2$. These two series statistically differed $(\mathrm{N}=5, \mathrm{~T}=15, \mathrm{P}=0.031)$. Calculated over the four testing sessions, the average ants' conditioning score equaled $72.3 \%$. The ants have thus duly distinguished and counted 1 and 2 elements though their relative position somewhat differed between training and testing.

During their training to 2 black squares set near the food versus 3 such squares set far from the food, the ants of colony K were meanly 9.0 in the vicinity of these two cues at any time, being thus able to see and memorize these two cues. They were tested in front of 2 and 3 black squares otherwise located than during training. After 7 training hours, however, the ants went somewhat mostly to the 2 squares: 46 ants were counted there while 21 ones were counted near the 3 squares. The ants' conditioning score equaled thus at that time $68.7 \%$. Summed by four, the numbers of ants counted near the 1 square were $9,11,9,9,8$, and those of ants counted near the 3 squares were 3 , $4,4,5,5$. These two series of values significantly differed $(\mathrm{N}=5, \mathrm{~T}=15, \mathrm{P}=0.031)$. After 24 training hours, the ants again went somewhat mostly to the 2 squares, being 46 in doing so, while 23 ants went to the 3 squares. The ants had thus at that time a conditioning score of $66.7 \%$. Summed by four, the numbers of ants having reacted to the 2 squares were $9,9,12,12,4$, and those of ants having reacted to the 3 squares were $4,5,5,6,3$. These two series significantly differed $(\mathrm{N}=5, \mathrm{~T}=15, \mathrm{P}=0.031)$. Tested after 31 training hours, the ants went more promptly essentially to the 2 squares: 41 ants did so while 11 ants went to the 3 squares, the ants' conditioning equaling thus $78.8 \%$. Summed by four, the numbers of ants sighted near the 2 squares were $10,6,5,7,13$, and those of ants sighted near the 3 squares were $2,2,2,1,4$. The two obtained series were statistically different $(\mathrm{N}=5, \mathrm{~T}=15, \mathrm{P}=$ 0.031). After a total of 48 training hours, the ants again went essentially, though less promptly, to the 2 squares, being 47 in doing so while 22 went to the 3 squares. The ants' conditioning score equaled thus $68.1 \%$. Summed by four, the numbers of ants having approached the 2 squares were $7,9,8,9,14$, and those of ants having approached the 3 squares were $2,4,6,4,6$. These two series significantly differed $(\mathrm{N}=5, \mathrm{~T}=15, \mathrm{P}=0.031)$. Calculated over the four testing sessions, the ants' average conditioning score equaled $70.6 \%$. The ants have thus well counted 2 and 3 squares even if these squares were otherwise positioned during testing and training.

While being trained to 3 black squares set near the food and 4 such squares set far from the food, the ants of colony L were meanly 7.3 at any time in the vicinity of these two cues, having the possibility to see and memorize them. Tested after 7 training hours, these ants went somewhat mostly to the 3 squares, being 61 in doing so while 34 ants went to the 4 squares. The ants' conditioning score equaled thus $64.2 \%$ at that time. Summed by four, the numbers of ants sighted near the 3 squares were $14,11,15,12,9$, and those of ants sighted near the 4 squares were $6,6,10$, 9,4 . These two series were statistically different $(\mathrm{N}=5, \mathrm{~T}=15, \mathrm{P}=0.031)$. After 24 training hours, the ants went more promptly mostly to the 3 squares: they were 47 in doing so while 18 ants went to the 4 squares. The ants presented thus a conditioning score of $72.3 \%$ at that time. Summed by four, the numbers of ants counted near the 3 squares were $8,8,10,9,12$, and those of ants counted near the 4 squares were $1,4,5,4,4$. These two series of values significantly differed $(\mathrm{N}=5, \mathrm{~T}=15, \mathrm{P}=0.031)$. After having been trained for 31 hours, the ants went again, thought somewhat less, mostly to the 3 squares: 59 did so and 28 ants went to the 4 squares, the ants' conditioning score equaling thus $67.8 \%$. Summed by four, the numbers of ants approaching the 3 squares were $6,18,8,16,11$, and of ants approaching the 4 squares were $2,8,7,7,4$. These two series statistically differed $(\mathrm{N}=5, \mathrm{~T}=15, \mathrm{P}=$ 0.031 ). After a total of 48 training hours, the ants again reacted mostly to the 3 squares: 58 ants did so while 31 ones reacted to the 4 squares. The ants' conditioning score equaled thus at that time 65.2. Summed by four, the numbers of ants moving to the 3 squares were $10,9,12,9,12$, and those of ants moving to the 4 squares were 5,5 , $5,5,11$. These two series significantly differed $(\mathrm{N}=5, \mathrm{~T}=15, \mathrm{P}=0.031)$. Calculated over the four testing sessions, the ants' average conditioning score equaled $66.2 \%$. The ants have thus correctly counted and discriminated 3 and 4 elements even if those they saw during testing were differently positioned than those they saw during training.

\section{Copyrights}

Copyright for this article is retained by the author(s), with first publication rights granted to the journal.

This is an open-access article distributed under the terms and conditions of the Creative Commons Attribution license (http://creativecommons.org/licenses/by/4.0/). 